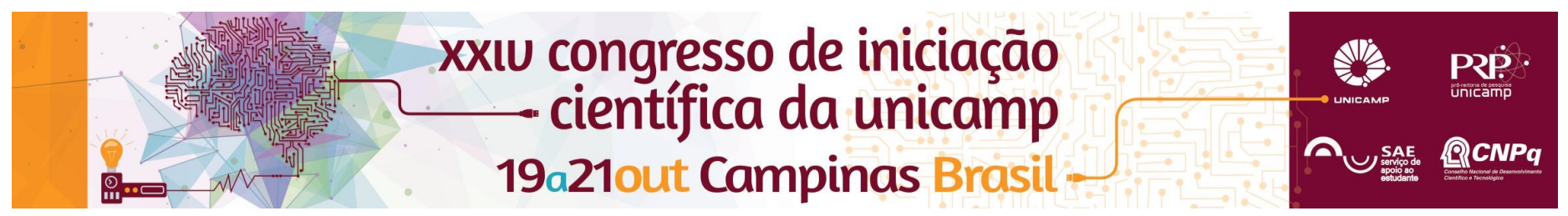

\title{
Monitoring of air flow through air valves
}

\section{Pedro P. Pellegrino*, Yvone de F. L. De Lucca, José G. Dalfré Filho}

\begin{abstract}
During operation, air can penetrate into water pipelines. Therefore, air valves are used to expel or allow the air into the pipes, through a designed orifice, and this flow is complex. The aim of this work was to develop an electronic monitoring and control system for air valves.
\end{abstract}

\section{Key words:}

air valves, air inflow/outflow, monitoring and control

\section{Introduction}

Air can penetrate into pipelines during operation of pipelines. The proper functioning of a water supply system must occur when emptying or filling a pipeline. To that, air valves are used. The aim of this work was to develop an electronic monitoring and control system for these valves.

\section{Results and Discussion}

A test facility was built in the Laboratory of Hydraulics and Fluid Mechanics at FEC-Unicamp (Figure 1).

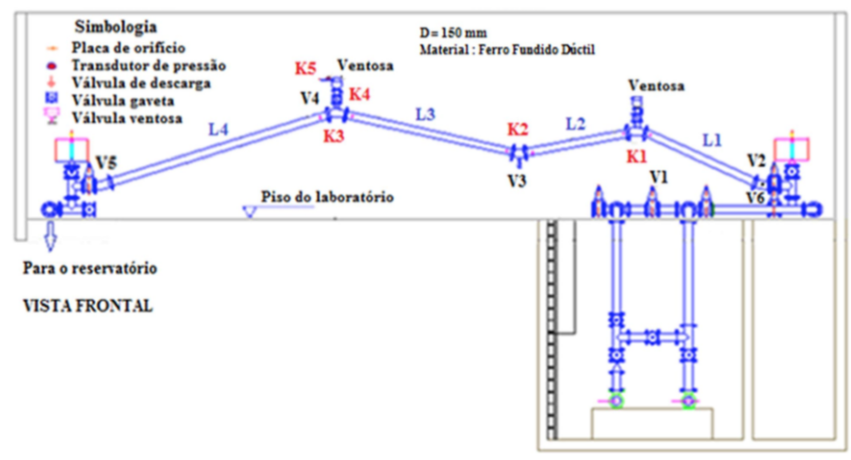

Figure 1. Air valve facility. Source: Aquino (2013).

As the presence of air is evidenced in high points, the air valve is used there (point K3). A triple function air valve was chosen. Its diameter is of $50.00 \mathrm{~mm}$. Some other instruments were used: a calibrated orifice plate (K5) for control and monitoring of air flow; an electromagnetic flowmeter (Conaut Optiflux 2100 C, 0-150 L/s) and a pressure transducer (Jumo dTRANS) to measure the pressure in the pipe (K4), its output signal is a DC current proportional to the inlet pressure, $4-20 \mathrm{~mA}, 0-2500 \mathrm{kPa}$. Also, two differential pressure transducers were used for measuring air pressure: Smar transducer, 4-20 mA, 0-980 $\mathrm{kPa}$, to measure the differential pressure between the extreme points of the air valve (K3) and; Novus transducer, 4-20 mA, 0-10 kPa, to measure the pressure difference between the extreme points of the orifice plate (K5). For the acquisition and recording of analog and digital data, a FieldLogger Novus was applied. The analog input channels can be configured for reading voltage, current and thermocouples. These entries have the accuracy of an A/D converter, 24-bit, $1000 \mathrm{~Hz}$. Digital channels can be configured as input or output. The configuration software allows collection and export of log data and status information. To unite all these functions and instruments, we have enhanced a connection panel in this work (Figure 2). It consists of a circuit breaker, a transformer, a transmitter with 10 channels and the logger. Pressure transmitters are all powered by this circuit. The flowmeter is connected to the power grid of the laboratory and connected to the FieldLogger

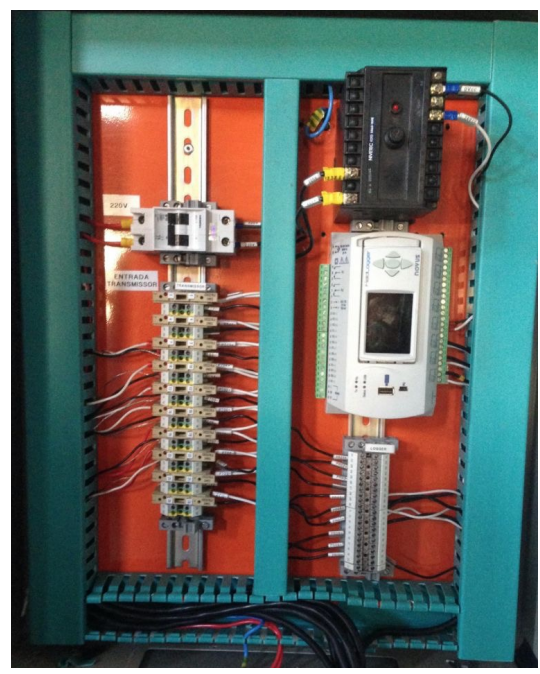

Figure 2. Connection panel.

\section{Conclusions}

The work highlighted the need of use of automatized air valves in pipelines. Sanitation Companies usually lack of skilled manpower for rapid monitoring service and operation of these valves, due to its complex operation. If proper instrumentation and automation is used, it is possible to implement a smart system to fully implement management in water systems.

\section{Acknowledgement}

We thank PIBIC-SAE, FAPESP (2010/51522-9), $\mathrm{PhD}$ candidate Genivaldo A. Aquino and Technicians Jefferson C. Rocha and Marcelo Balbino.

AQUINO, G.A. (2013) Caracterização do escoamento de ar em adutoras e válvulas ventosas. Dissertação. Unicamp, Campinas, Brasil. 